\title{
Spatial and Statistical Analysis of Leptospirosis in Guilan Province, Iran
}

\author{
A. Mohammadi Nia ${ }^{\text {a, }}$, A. Alimohammadi ${ }^{\text {a }}$, R. Habibi ${ }^{\text {a }}$, M. R. Shirzadi ${ }^{\text {b }}$ \\ ${ }^{a}$ Dept. of Geomatic Engineering, K. N. Toosi University of Technology, Valy-Asr Street, Mirdamad Cross, Tehran, Iran - \\ (Ali.mohamadinia, Alimohammadi \& Rhabibi)@kntu.ac.ir \\ ${ }^{\mathrm{b}}$ Centre for Disease Control and Prevention (CDC), Iran Ministry of Health \& Medical Education, Tehran, Iran
}

KEY WORDS: GIS, Spatial Distribution, Spatial Statistics, Infectious Disease, Leptospirosis

\begin{abstract}
:
The most underdiagnosed water-borne bacterial zoonosis in the world is Leptospirosis which especially impacts tropical and humid regions. According to World Health Organization (WHO), the number of human cases is not known precisely. Available reports showed that worldwide incidences vary from 0.1-1 per 100000 per year in temperate climates to $10-100$ per 100000 in the humid tropics. Pathogenic bacteria that is spread by the urines of rats is the main reason of water and soil infections. Rice field farmers who are in contact with infected water or soil, contain the most burden of leptospirosis prevalence. In recent years, this zoonotic disease have been occurred in north of Iran endemically. Guilan as the second rice production province (average $=750000000 \mathrm{Kg}$, $40 \%$ of country production) after Mazandaran, has one of the most rural population (Male $=487679$, Female $=496022)$ and rice workers $(47$ 621 insured workers) among Iran provinces. The main objectives of this study were to analyse yearly spatial distribution and the possible spatial clusters of leptospirosis to better understand epidemiological aspects of them in the province. Survey was performed during the period of 2009-2013 at rural district level throughout the study area. Global clustering methods including the average nearest neighbour distance, Moran's I and General G indices were utilized to investigate the annual spatial distribution of diseases. At the end, significant spatial clusters have been detected with the objective of informing priority areas for public health planning and resource allocation.
\end{abstract}

\section{INTRODUCTION}

Leptospirosis is an illness characterized by fever, headache, and myalgia that lack of timely diagnosis would lead to death. It's a zoonosis disease which impacts both humans and animals in the world. Regarding to World Health Organization (WHO), the number of human cases is not known precisely because of lack of disease awareness and difficulties in carrying out laboratory confirmation tests. However, available reports showed that worldwide incidences vary from $0.1-1$ per 100000 per year in temperate climates to $10-100$ per 100000 in the humid tropics (WHO, 2014).The estimated burden of disease is 500000 persons annually (Abela-Ridder, 2010).Both wild and domestic animals are the main reservoirs of leptospirosis especially dogs and rats. Pathogenic bacteria which spread by the urines of infected animals (either by direct contact or through contaminated soil or water) is the main reason of water and soil infections (Faine, 1994). Skin abrasion and wounds are the best way for leptospires to penetrate through the body of another host and continue its life. Moreover, suitable environmental waters and moist soil can help leptospires survive and propagate in warm temperature (Honarmand, 2011). As an occupational disease, leptospirosis is associated with people who are in contact with water or sewage such as rice field workers, fish workers, miners and sewage workers. Rice field workers who are in contact with infected water or soil, contain the most burden of leptospirosis prevalence (Schneider, 2013).

A complex interaction between humans, animal reservoirs, and the environment lead to leptospirosis. It may occur both in urban or remote rural areas with limited access. According to nature of this disease, rural cases are greater because of proper environmental factors (Wivanitkit, 2006). Among different

\footnotetext{
* Corresponding author. This is useful to know for communication with the appropriate person in cases with more than one author.
}

environmental risk factors and various ecological settings, contact with animals, high rainfall and flooding play the most important role in leading and propagation of leptospirosis (Lau, 2012). According to unique ecological settings, a comprehension of the effective risk factors will be helpful to understand the transmission cycle and also the way of disease propagation. As a significant public health problem, leptospirosis occurs worldwide especially south-east of Asia and developing countries (Brown, 2010). It's endemic in many countries and outbreaks have been observed throughout the world during the past few years. (Sugunan, 2009; Zaki 1995; Barcellos, 2001).

In recent years, this zoonotic disease have been occurred in north of Iran endemically. Guilan as the second rice production province (average $=750 \quad 000 \quad 000 \mathrm{Kg}, \quad 40 \%$ of country production) after Mazandaran, has one of the most rural population $($ Male $=487679$, Female $=496$ 022) and rice workers (47 621 insured workers) among Iran provinces. It has recorded highest incidences of leptospirosis in the country (maximum at Jun 2010) and have suitable factors for leptospirosis outbreak. Guilan is located in north of Iran, near Caspian Sea with appropriate conditions for the prevalence of leptospirosis, but there is not enough statistical information and updated data about epidemiology of this disease in the area. To the best of our knowledge, no efforts have been made with regard to spatial analyses of leptospirosis distribution in Guilan but studies mostly were about spatial components and focused on the characteristics of the individual patients and vector or reservoirs of their study area. For these reasons, the main objective of this study is to analyses the spatial distribution as well as possible clusters of leptospirosis over the area at rural district level. 
Moreover, we tried to investigate the impact of environmental factors on leptospirosis which have been obtained from synoptic stations distributed through the area.

\section{MATERIALS AND METHODS}

\subsection{Study area}

Guilan province with 2480874 populations (Male = 1231933 , Female $=1248941$ ) according to 2011 enumeration, covers the area of 14041 square kilometres and includes 109 rural district (Fig 1). Guilan is trapped between south-west of Caspian Sea and north of Alborz Mountains (Average Height $=3000 \mathrm{~m}$ ). Neighbor provinces are Ardabil (West), Zanjan and Qazvin (South) and Mazandaran (North). Regarding to location condition, it has a temperate and humid climate along the Caspian coast and southern forests.

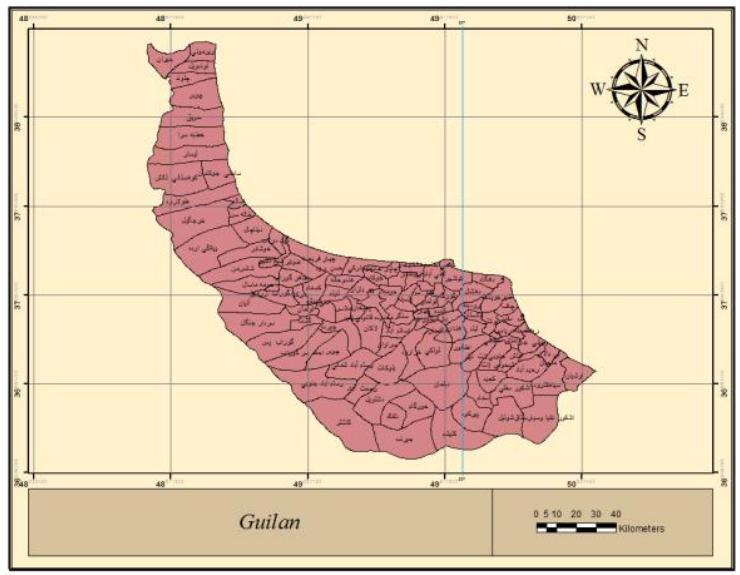

Figure 1. Guilan province and rural districts

\subsection{Data collection}

The estimated population census counts for period 2009-2013 were obtained from the Statistical Center of Iran. The data of this analytical survey were reported by Centers for Disease Control and prevention (CDC) of 109 rural districts including number of cases and date of occurrence from 2009 to 2013. For investigating the effect of environmental parameters, minimum of daily temperature, maximum of daily temperature, average temperature, precipitation, average humidity, average wind speed and average vapor pressure were collected from 12 synoptic weather stations as the environmental conditions.

\subsection{Data Analysis}

We used geographic information system (GIS) and ArcGIS 10.1 as the software for making data ready, understanding disease dynamics and assess the villagers' exposure. First step as GISready was dividing number of reported cases for each rural district to its yearly population from 2009 to 2013. Then, global clustering techniques (average nearest-neighbor distance, Moran's I and general G) were used for analyzing and evaluating yearly distribution. Finally, spatial clusters of leptospirosis were detected. For evaluating null hypothesis, different tests have been proposed. So, three different methods including the average nearest-neighbour distance (ANN), Moran's I and General G indices were used, for each year.

"Average nearest neighbour calculates a nearest neighbour index based on the average distance from each rural district to its nearest neighbour. Moran's I given a set of weighted rural districts, identifies where high or low values cluster spatially, and features with values that are very different from surrounding feature values" (ESRI, 2015; Mitchell, 2005):

$$
I=\frac{N}{S_{0}} \frac{\sum_{i=1}^{N} \sum_{j=1}^{N} w_{i j}(\mathrm{xi}-\overline{\mathrm{x}})\left(\mathrm{x}_{\mathrm{j}}-\overline{\mathrm{x}}\right)}{\sum_{i=1}^{N}(\mathrm{xi}-\overline{\mathrm{x}})^{2}}
$$

$S_{0}=\sum_{i=1}^{N} \sum_{j=1}^{N} w_{i j}$

where $\quad$ Wij $=$ spatial weight between the case $\mathrm{i}$ and $\mathrm{j}$

$\mathrm{N}=$ total number of disease cases

$\mathrm{S} 0=$ aggregate of all spatial weights

$\mathrm{xi}, \mathrm{xj}=$ numbers of cases in the ith and $\mathrm{jth}$ provinces

"Given a set of weighted data points, the Getis-Ord Gi* statistic identifies those clusters of points with values higher in magnitude than you might expect to find by random chance. (For line and polygon features, centroids are calculated prior to analysis.)" (ESRI, 2015). General G is given as (Getis, 1992):

$$
G=\frac{\sum_{i=1}^{N} \sum_{j=1}^{N} w_{i j} x_{i} x_{j}}{\sum_{i=1}^{N} \sum_{j=1}^{N} x_{i} x_{j}}, \forall \mathrm{j} \neq \mathrm{i}
$$

Local indices indicate disease locations and their degrees. Also, define that observed spatial pattern of a disease is unexpected or relative to a null hypothesis. Difficulties arise in local evaluations, however, because each comparison is a separate hypothesis test. Local indicators of spatial association were proposed in Getis and Ord (1992) and Anselin (1995). So, local Indices including Local Moran's I and Local $\mathrm{G}_{i}$ applied in the study. The equation is as below:

$$
\begin{gathered}
I_{\mathrm{i}}=\mathrm{Zi}_{\mathrm{i}} \sum_{i=1}^{N} w_{i j} z_{j} \\
z_{i}=\left(y_{i}-\bar{y}\right) / S
\end{gathered}
$$

where $\quad W_{i j}=$ spatial weight between $\mathrm{i}^{\text {th }}$ and $\mathrm{j}^{\text {th }}$ provinces

$\mathrm{Z}_{\mathrm{i}}, \mathrm{Z}_{\mathrm{j}}=$ values of $\mathrm{z}$-score in $\mathrm{i}^{\text {th }}$ and $\mathrm{j}^{\text {th }}$ provinces

$\mathrm{y}_{\mathrm{i}}=$ number of cases for $\mathrm{i}^{\text {th }}$ province

$\mathrm{S}=$ aggregate of all spatial weights

Local $\mathrm{G}_{\mathrm{i}}$ used to detect possible non-stationary in data, when clusters of similar values are found in specific subregions of the study area (Anselin, 1995).

$$
G_{i}=\frac{\sum_{j \neq i} w_{i j} y_{j}}{\sum_{i=1}^{N} y_{i}}
$$

where $\quad W_{i j}=$ spatial weight between $\mathrm{i}^{\text {th }}$ and $\mathrm{j}^{\text {th }}$ provinces

$\mathrm{y}_{\mathrm{i}}, \mathrm{y}_{\mathrm{j}}=$ number of disease cases for $\mathrm{i}^{\text {th }}$ and $\mathrm{j}^{\text {th }}$ provinces Interpolation is a procedure to predict values of attributes at points that are not sampled. There is no single preferred method for data interpolation. Aspects of selecting appropriate interpolation method need to be based on the actual data, the level of accuracy required, and the time or computer resources 
available. Selecting an appropriate spatial interpolation method is fundamental because different methods of interpolation can result in different results (Legendre, 1998). Maybe, the most utilized and simple interpolation method is Inverse distance weighting (IDW). So, we used IDW for interpolation of environmental parameters in this study. It's based on the premise that the predictions are a linear combination of available data. The interpolating function is (Shepard, 1968):

$$
\begin{gathered}
Z(x)=\sum_{i=1}^{n} w_{i} z_{i} / \sum_{i=1}^{n} w_{i} \\
w_{i}=d_{i}
\end{gathered}
$$

Where $\mathrm{Z}(\mathrm{x})=$ predicted value at an interpolated point

$\mathrm{Zi}=$ predicted value at known point $\mathrm{i}$

$\mathrm{n}=$ total number of known points

$\mathrm{di}=$ distance between point $\mathrm{i}$ and prediction point

wi $=$ weight assigned to point $\mathrm{i}$

$\mathrm{u}=$ weighting power

\section{RESULTS}

Figure 2 shows leptospirosis incidences (1/100 000) and annual case-fatality rate in Guilan province from 2009 to 2013. During these 5 years, a total of 657 leptospirosis cases were reported. Annualized average incidence ranged from 6.13 to 33.94 during the period 2009-2013. The highest incidence was observed in 2010. Number of yearly occurrence exceeded 100 only in 2010 and 2011. A total of 9 deaths were reported from 2009 to 2013, with no deaths in 2011 and 2012.

The annual average leptospirosis incidences for each rural district for the 5 years are shown in Figure 3. As can be seen, leptospirosis was mainly prevalent in the central especially at Some e Sara county (including rural districts: Goorab Zarmikh, Hend Khale, Kasma, Lifeshagerd, Merkyeh, Zyabar, Taher Goorab). The number of epidemic rural districts that had leptospirosis records was respectively $31,51,52,34$ and 43 for 2009-2013.

We used ArcGIS 10.1 for checking null hypothesis. Results of three methods showed that in all 5 years, we had highly spatial autocorrelation in Guilan province. All of them had highlyclustered reports.

Considering the ratio of male and female workers who have been contaminated, more than 60 percent of patients were men workers during 2009 to 2013 (Table 4). So, results showed that men are more vulnerable against leptospirosis and need more attention and knowledge about this disease as the main target of prevention programs.

Regarding to the recorded dates for disease incidence in patients, period of leptospirosis prevalent is from April to October. We could consider five months including May, Jun, July, August, and September as common months during 2009 to 2013. Not having any recorded leptospirosis patient at the other months of year, maximum disease incidence was happened at Jun (2009, 2010, and 2011), May (2012) and August (2013). Reports indicate that leptospirosis occurs in paddy season and months after when workers go to rice fields (Figure 5).

Result of local Moran's I clustering method showed one cluster at 2009 and 2010 (HH and LH), two clusters at 2011 (HH and LH) and three clusters at 2012 (HH, LH and HL) and 2013 (HH, LH and HL). "HL" will indicate rural district has high incidence but is surrounded by rural districts with low incidence, "HH" express rural district has high incidence and is surrounded by with high values (LH). Clusters are located mostly at centre and

\begin{tabular}{|l|c|c|c|c|c|}
\hline Sex\Time & 2009 & 2010 & 2011 & 201 & 201 \\
& & & & 2 & 3 \\
\hline men & 72 & 67 & 61 & 70 & 64 \\
women & 28 & 33 & 39 & 30 & 36 \\
\hline
\end{tabular}

Table 4 . Percent of leptospirosis genders from 2009 to 2013

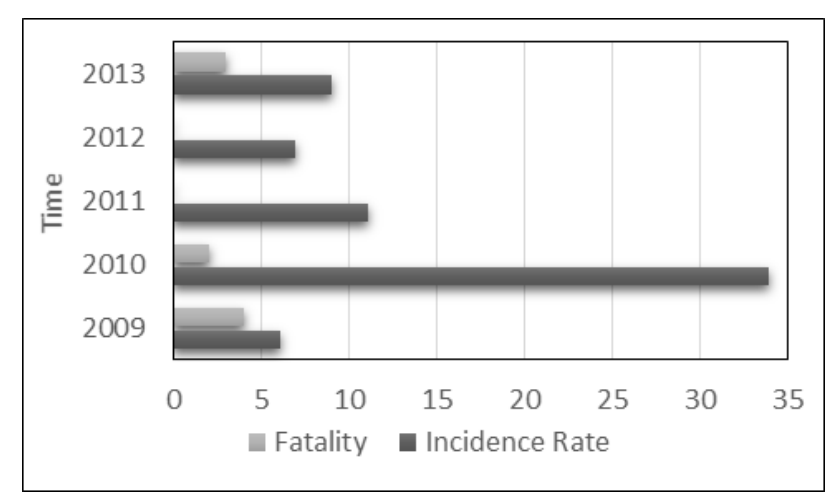

Figure 2. Annual leptospirosis incidence in Guilan province. Figure 3. The annual average leptospirosis incidences of each rural district in Guilan province for 2009-2013 ( $\mathrm{r} \mathrm{a}, \mathrm{b}, \mathrm{c}, \mathrm{d}, \mathrm{e}$ )

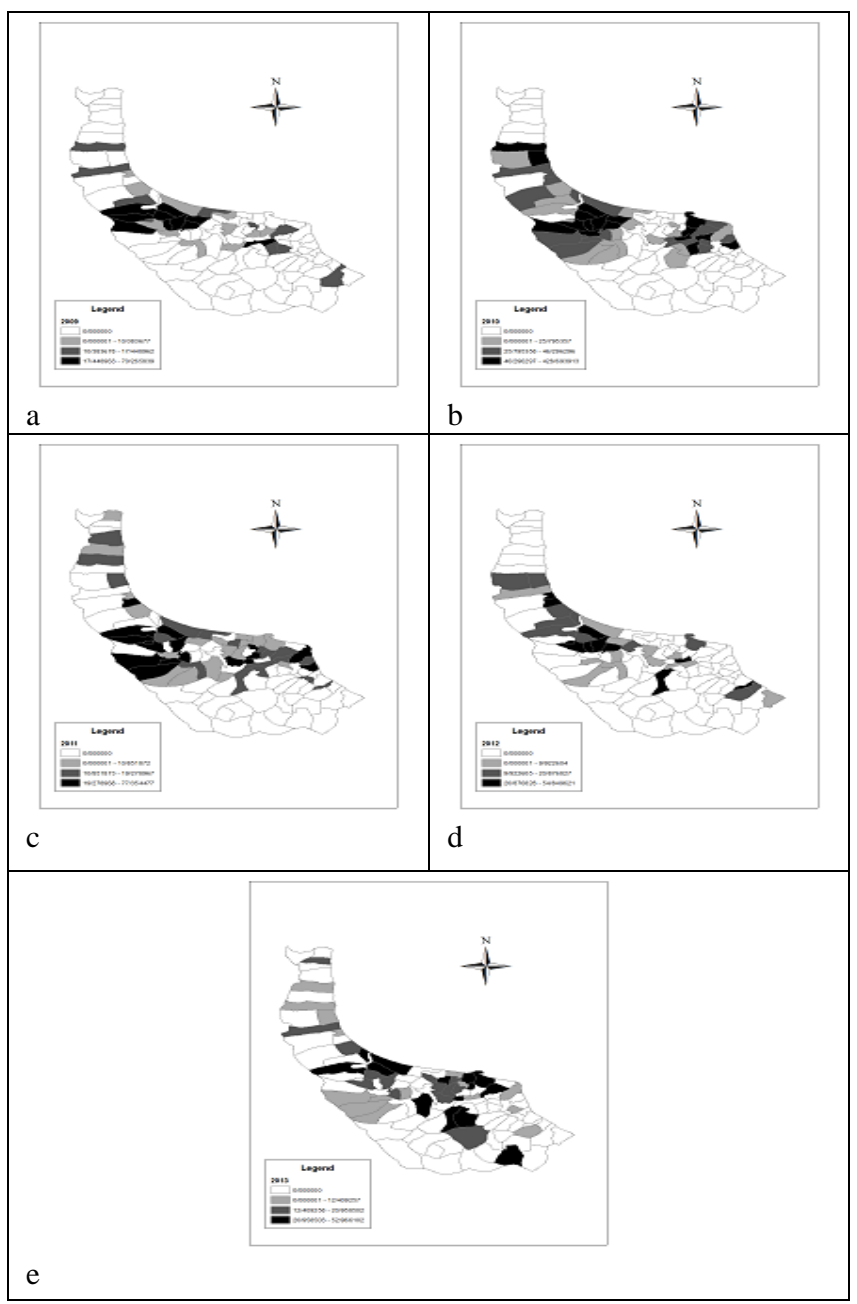




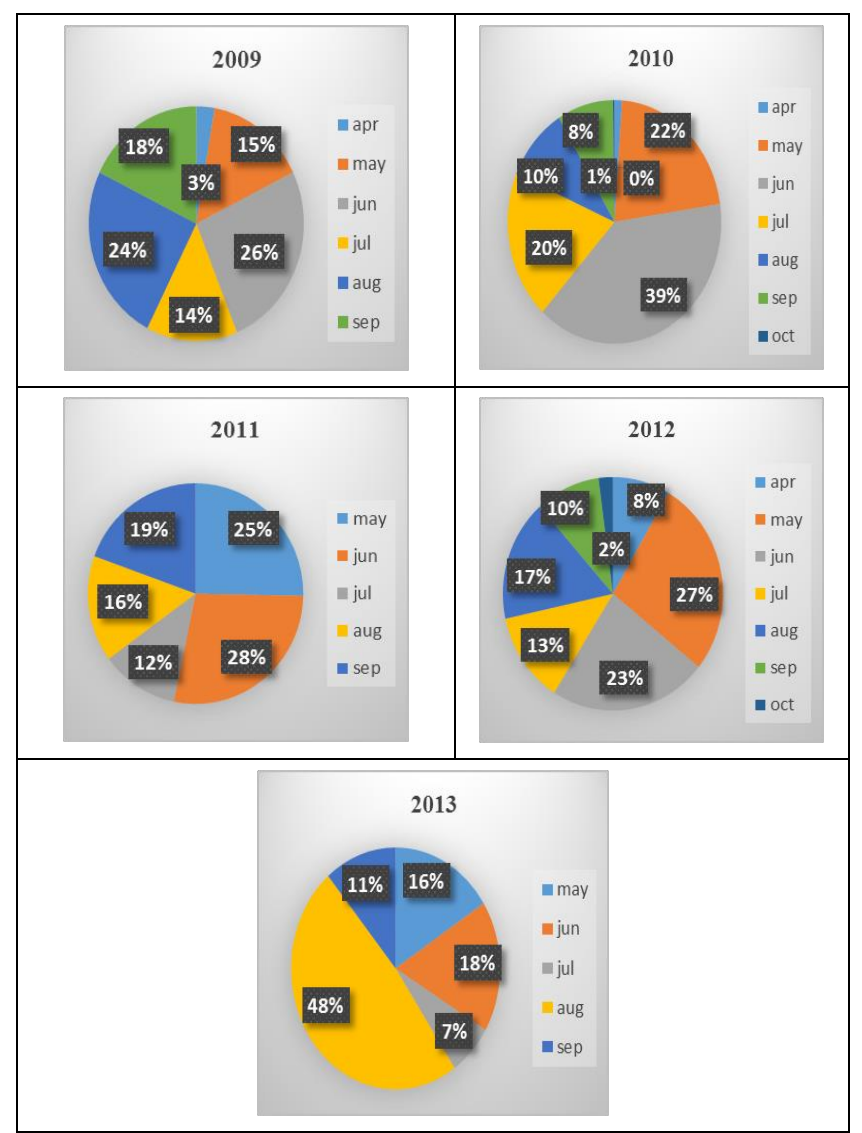

Figure 5. The monthly leptospirosis incidences of all rural districts in Guilan province for 2009-2013.

west of Guilan province (Figure 6).

By comparison of local Moran's I and Getis-Ord results, both identified the location of clusters almost the same. Getis showed a cold spot cluster at east of province in all 5 years and hot spot at center and west (Figure 7).

Annual and monthly average values of environmental parameters gathered from 12 synoptic stations were computed and used for interpolation. Results indicate that high incidences are located among and near 4 stations of Bandar e Anzali, Rasht, Masuleh and Rash-Agriculture. Understanding from interpolation results, "precipitation", "average humidity" and "average Vapor" have related maps in comparison with Moran's I and Getis maps. Maximum yearly value for these parameters recorded at Bandar e Anzali, Rasht-Agriculture and Bandar e Anzali consecutively (Table 8).

\section{DISCUSSION}

In the country, some regions are so appropriate for prevalence of leptospirosis. Temperate climate, many surface waters and lots of rodents that live closely to villages make north of Iran (especially Guilan province) as one of risky regions. Main activity of villagers in this region is rice farming. Rice paddies must always be wet and the main source of irrigation of rice farms are rivers and ponds (the most suitable place for rodents). According to these reasons, this region was selected for study. Regarding to the nature of leptospirosis occurrence and because the number of urban patients was so little in comparison to rural districts, we just considered rural patients in this study regardless of urban residents. Also, the location of leptospirosis is always in farm lands where disease transformation happen but

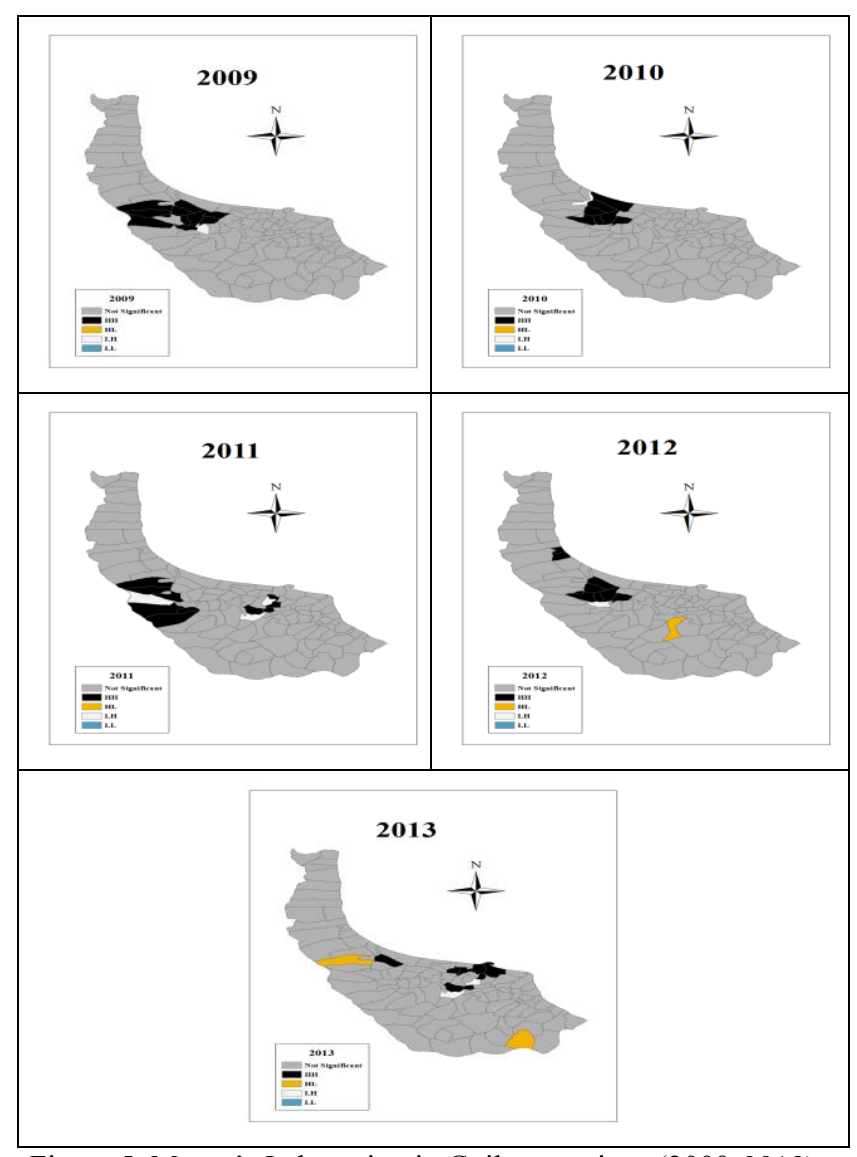

Figure 5. Moran's I clustering in Guilan province (2009-2013).

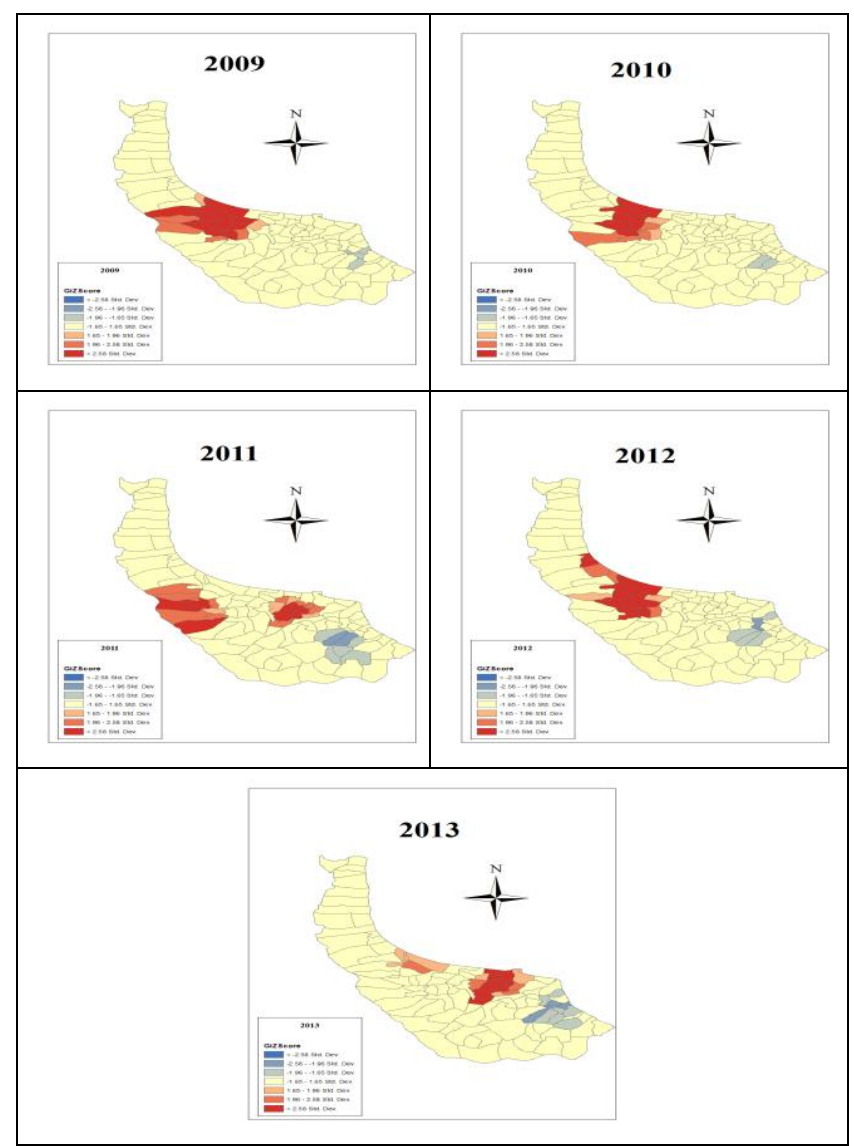

Figure 7. Getis clustering in Guilan province (2009-2013). 


\begin{tabular}{|c|c|c|c|c|c|c|c|}
\hline Station & $\mathbf{a}$ & b & c & d & e & f & g \\
\hline \multirow[t]{2}{*}{ Astara } & & $25 / 8$ & $15 / 5$ & $105 / 9$ & $80 / 0$ & & $14 /$ \\
\hline & $7 / 9$ & 6 & 3 & 2 & 4 & $1 / 3$ & 9 \\
\hline Bandar e & $10 / 3$ & $25 / 2$ & $16 / 4$ & $119 / 9$ & $83 / 4$ & & $16 /$ \\
\hline Anzali & 5 & 9 & 9 & 1 & 4 & $3 / 1$ & 6 \\
\hline \multirow[t]{2}{*}{ Daylaman } & & $24 / 1$ & & & $64 / 6$ & & \\
\hline & $0 / 31$ & 3 & $11 / 7$ & $35 / 78$ & 8 & $3 / 2$ & $9 / 4$ \\
\hline \multirow{2}{*}{ Jirandeh } & & $23 / 4$ & $11 / 5$ & & $59 / 2$ & & \\
\hline & $2 / 05$ & 1 & 8 & $26 / 03$ & 3 & $5 / 5$ & $8 / 4$ \\
\hline \multirow[t]{2}{*}{ Kyiashahr } & & $26 / 1$ & $16 / 9$ & $101 / 7$ & $79 / 7$ & & $16 /$ \\
\hline & $8 / 51$ & 6 & 8 & 6 & 4 & 2 & 3 \\
\hline \multirow[t]{2}{*}{ Lahijan } & & $28 / 8$ & $16 / 8$ & & $78 / 7$ & & $15 /$ \\
\hline & $7 / 7$ & 6 & 7 & $98 / 02$ & 2 & $1 / 1$ & 8 \\
\hline \multirow[t]{2}{*}{ Manjil } & & $31 / 3$ & $17 / 0$ & & $64 / 6$ & & $12 /$ \\
\hline & $7 / 21$ & 8 & 4 & $17 / 75$ & 8 & $5 / 1$ & 9 \\
\hline \multirow[t]{2}{*}{ Masuleh } & & $23 / 9$ & $11 / 5$ & & $77 / 0$ & & $11 /$ \\
\hline & $2 / 78$ & 1 & 8 & $74 / 02$ & 9 & $2 / 1$ & 1 \\
\hline \multirow[t]{2}{*}{ Rasht } & & & $15 / 9$ & & & & $15 /$ \\
\hline & $7 / 96$ & $27 / 8$ & 5 & $82 / 96$ & $83 / 2$ & $1 / 4$ & 9 \\
\hline Rasht- & & $28 / 9$ & $15 / 9$ & & $83 / 6$ & & $15 /$ \\
\hline Agriculture & $6 / 99$ & 8 & 2 & $85 / 09$ & 6 & $1 / 3$ & 9 \\
\hline \multirow{2}{*}{ Rudsar } & & $25 / 9$ & $16 / 9$ & & $78 / 6$ & & \\
\hline & $8 / 65$ & 1 & 8 & $81 / 82$ & 6 & $1 / 7$ & 16 \\
\hline \multirow[t]{2}{*}{ Talesh } & & & $16 / 5$ & & $78 / 3$ & & $15 /$ \\
\hline & $8 / 75$ & 26 & 2 & $77 / 25$ & 2 & $1 / 6$ & 6 \\
\hline
\end{tabular}

Table 8. Yearly average values of environmental parameters $(\mathrm{a}=$ minimum of daily temperature, $b=$ maximum of daily temperature, $\mathrm{c}=$ average temperature, $\mathrm{d}=$ precipitation, $\mathrm{e}=$ average humidity, $\mathrm{f}=$ average wind speed and $\mathrm{g}=$ average vapor pressure)

we supposed that workers almost live near farm lands and the address of patients that have been gathered from CDCs were considered as the analysis unit. As the gathering system for recording leptospirosis patients started at 2009, there was gap in the address of some patients at the first year. So, patients without address were removed from study. All cases have been tested at clinical laboratory and deterministic results (positive) were used at the study. According to the statements of experimental farmers and rice experts, the most suitable time for rice planting and cultivation start at half of April and end at half of August (CIDNG, 2014). Our study confirmed that the period of leptospirosis occurrence in Guilan is mostly from May to August which is coinciding summer season when the rice cultivation going to end. Moreover, it is obtainable from results that "Jun" have the most victims among other months especially at 2010. An endemic period was discovered at 2010 with 33.94 incidence rate that concerned privacy policies. Results showed that both genders were vulnerable to the disease. However, majority of cases were discovered in males. Maybe the main reason is less covering and higher environmental and social interactions than the women. South of Guilan is covered with Alborz mountains and North (coastline) have urban texture. Center of province include farm lands and have best condition for leptospirosis prevalence. Clustering methods from 2009 to 2012 (except 2013) confirmed this reality and showed that clusters are almost in center of province (especially at Some Sara county). Also, visual comparison of interpolation maps and clustering expressed that 3 of 7 environmental parameters have correlation with leptospirosis (was indicated at results section) and 4 stations of 12 are so vital because prevalence have been occurred near these stations.

Many research have been done around the world about leptospirosis but with regard to our research, a little study have been performed in Iran and they have almost been investigated clinical aspects of leptospirosis. It could be concluded that leptospirosis is a serious public health problem in Guilan, especially centre of province in Some Sara county with highest number of clusters. Therefore, we suggest further studies focus more specific socio-economic factors effecting the spatial and temporal patterns of leptospirosis. We hope this study have guidelines for prevention programs and control strategies to higher risk areas.

\section{REFERENCES}

Abela-Ridder, B., 2010. Estimating the burden of human leptospirosis. International journal of antimicrobial agents, 36, S5-S7

Anselin, L. (1995). Local Indicators of spatial association LISA. Geographical Analysis, 27:93-115.

Barcellos C, 2001. The place behind the case: leptospirosis risk and associated environmental conditions in a flood-related outbreak in Rio de Janeiro. Cad Saude Publica 17:59-67

Brown, P. D., 2010. Environmental risk factors associated with leptospirosis among butchers and their associates in Jamaica. The international journal of occupational and environmental medicine, 2(1 January).

Co-operation of Irrigation and Drainage Networks of Guilan (CIDNG), 2014. Available at: http://www. abyariguilan.ir/

Environmental Systems Research Institute (ESRI), 2015. Available at: http://www.esri.com/

Faine S., 1994. Leptospira and leptospirosis. CRC, London

Getis, A., 1992. The analysis of spatial association by use of distance statistics. Geographical analysis, 24(3), 189-206.

Honarmand, H. R., 2011. Detection of Leptospires serogroups, which are common causes of human acute leptospirosis in Guilan, Northern Iran. Iranian journal of public health, 40(1), 107.

Lau, C. L., 2012. Leptospirosis in American Samoa-estimating and mapping risk using environmental data. PLoS Negl Trop Dis: e1669.

Legendre, P., 1998. Numerical Ecology, 2nd Edition, Elsevier, Canada.

Mitchell, A., 2005. The ESRI Guide to GIS Analysis. ESRI Press, Redlands, CA

Schneider, M. C., 2013. Leptospirosis: A silent epidemic disease. International journal of environmental research and public health, 10(12), 7229-7234.

Shepard, D., 1968. A Two-dimensional Interpolation Function for Irregularly-spaced Data. ACM New York, NY, USA

Sugunan AP, 2009. Risk factors associated with leptospirosis during an outbreak in Middle Andaman, India. Indian J Med Res 130:67-73 
The International Archives of the Photogrammetry, Remote Sensing and Spatial Information Sciences, Volume XL-1/W5, 2015 International Conference on Sensors \& Models in Remote Sensing \& Photogrammetry, 23-25 Nov 2015, Kish Island, Iran

Wivanitkit, V., 2006. A note from a survey of some knowledge aspects of leptospirosis among a sample of rural villagers in the highly endemic area, Thailand. The international electronic journal of rural and remote health research, education, practice and policy. 6:526.

World Health Organization (WHO), 2015. Leptospirosis Burden Epidemiology Reference Group (LERG). Available at: http://www.who.int/zoonoses/diseases/lerg/en/index2.html

Zaki SR, 1995. Leptospirosis associated with outbreak of acute febrile illness with pulmonary haemorrhage, Nicaragua. The epidemic working group at Ministry of Health in Nicaragua. Lancet 347:535-536 